\title{
The Study of Fault Location Method Based on FTU Feeder Automation Technology
}

\author{
Zhou Jun ${ }^{*}$, Cao Ke-Zheng and Zheng Hong-Xia
}

Electrical Engineering Institute, Northeast Dianli University, Jilin, China

\begin{abstract}
With the development of power distribution automation system, feeder automation technology in the small current grounding system single-phase grounding fault location plays an important role. In the neutral arc suppression coil grounding system, because of the compensation effect of arc suppression coil, the system fault feature is not obvious. This paper puts forward a method of RL series branch parallel in arc suppression coil, when system single-phase grounding fault occurs, the series branch switch gets closed and acts on the neutral, that changes the compensation degree of arc suppression coil to zero sequence current in fault line, the change of zero sequence residual current being the biggest in the fault section from neutral to fault point. FTU is used to monitor the change in each fault line for fault regional location.
\end{abstract}

Keywords: Small current grounding, fault location, zero sequence current, feeder automation technology, arc suppression coil.

\section{INTRODUCTION}

Generally, networks with ungrounded neutral are used in the $6 \sim 66 \mathrm{kV}$ power distribution system in China. When single-phase grounding fault occurs in this voltage level of the system, the short circuit current is small, so is called the small current grounding system. Due to the small current grounding system in case of single-phase grounding fault, the three-phase line voltage still keeps symmetry, and the system is allowed running 1 to 2 hours on fault. So the reliability of power distribution system can be improved. But non-fault phase voltage raise at this moment, leading to single-phase grounding fault expands to two-phase or more point grounding fault unless finding the fault point and repairing in time. Because of the development of the power distribution network, the quantity of outgoing lines and wirecable mixed lines is increased, the whole system of capacitance current through the grounding point is too large to quench, causing arc over-voltage in single-phase grounding fault to the safe running of distribution system. Therefore, network neutral-point adopts the arc suppression coil grounding system in most places [5].

At present, for the theory of small current grounding system fault location can be divided into the following categories: injecting signal method, fault point probe method and fault location method that can be divided into impedance method and the traveling wave method. But impedance method range of application has a lot of limitations, and is not conducive to the practical application. Through building the distributed parameter model of network, an algorithm has been put forward that transmits line single terminal voltage and measures the current for fault location, it improves accu-

*Address correspondence to this author at the Electrical Engineering Institute, Northeast Dianli University, Jilin, China; Tel: 13504760968; E-mail: jlzhoujun@126.com racy of measurement by considering the influence of distributed capacitance in the algorithm [1]. Some papers have reported the use of the relationship between wavelet transform modulus maxima and voltage wave to determine wave head polarity. The arrival time of initial wave and the fault point reflection head-wave are captured to determine the time of traveling for wave, that for fault location [2]. One study puts forward the comprehensive use of fault initial voltage wave in end line, and fault initial current wave in bus terminal for implementing fast fault location [3]. In view of the application of fault line indicator, another study is proposed for fault point probe method. According to the characteristics of zero sequence current and zero sequence voltage before and after fault point in fault branch and non-fault branch, analyzing the magnetic field strength and electric field strength amplitude at the bottom of the fault branch, the phase of magnetic field advances electric field $\pi / 2$ at the bottom of non-fault branch and fault branch to line, but the situation is opposite at the bottom of fault branch forward line, so that puts forward a fault point probe method by using five harmonic zero sequence electric field and magnetic field [4]. From the current trend, based on all kinds of the system factors such as different voltage grade, complicated network topology, neutral grounding mode and transition impedance etc, the accurate fault location cannot be implemented with only one kind of method, so all sorts of location method fusion comprehensive localization method have become the focus of the present study.

Although the small current grounding system fault line selection and location technology has been researched for many years, and a variety of methods is put forward, at the same time corresponding protection devices are developed and acted, but the actual effect is not ideal, some methods only stay in the theoretical level. The phenomenon mainly has the following several reasons: neutral grounding mode, the size of the grounding resistance, power distribution network structure, current transformer and voltage transformer 


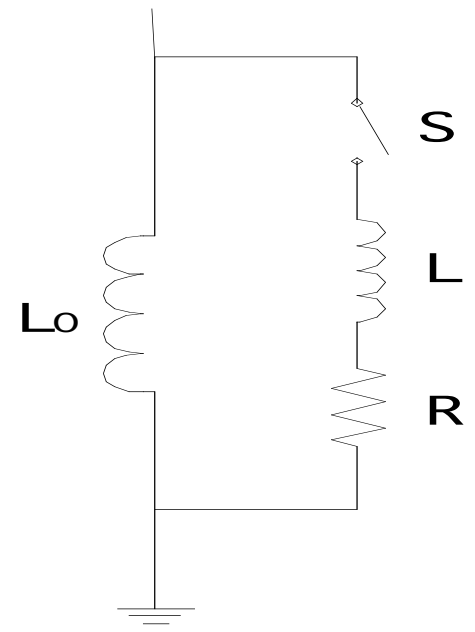

Fig. (1). The system neutral hardware structure.

testing equipment, unbalanced current in lines and the influence of fault switching Angle [6].

When single-phase grounding fault occurs in neutral arc suppression coil grounding system, neutral produces inductance current offset the original system of capacitive current partly, so as to reduce the fault point zero sequence current effectively, and quench electric arc. However, due to compensation effect of arc suppression coil, which makes the system fault characteristics not obvious, traditional method of fault line selection and location is failure. To solve the contradiction between arc suppression coil compensation effect and fault location technology, this paper puts forward a method of parallel RL series branch in the arc suppression coil, in which arc suppression coil compensation degree is changed shortly, making the zero sequence residual current by arc suppression coil compensation effect produce change temporarily. Its theoretical basis is the change of zero sequence residual current only in the loop from the neutral to the fault point via the fault line, as to distinguish the fault area and the non-fault area judgment conditions. With the development of distribution network automation, the small current grounding system single-phase grounding fault location method based on FTU feeder automation technology can be implemented. Installing FTU in the system on each node, dividing system feeder area, using the change of zero sequence residual current by RL series branch parallel in arc suppression coil in neutral, FTU monitors the changes in each node, and the small current grounding system singlephase grounding fault regional location can be implemented $[7,8]$.

\section{THE CHANGE OF ZERO SEQUENCE CURRENT ANALYSIS}

As the effect of arc suppression coil compensation, that makes system fault characteristics not obvious, fault and non-fault area cannot be distinguished. With method of residual current increment as a reference that changes neutral arc suppression coil compensation effect, this paper puts forward change zero sequence current in fault line by RL series branch parallel in arc suppression coil in neutral to distinguish between fault and non-fault area, it is distinguished from the method of residual current increment, that does not need to adjust arc suppression coil compensation directly to magnify the fault characteristics, and bigger fault current, leads to damage the system stability. RL series branch is only put into operation in time when single-phase grounding fault occurs, it produces initial half-wave and zero sequence residual current in fault line stack, making the fault area zero sequence current short-term change obvious. Fig. (1) shows the system neutral hardware structure.

As shown in Fig. (1), $\mathrm{L}_{0}$ is arc suppression coil, $\mathrm{R} \& \mathrm{~L}$ are resistance and inductance of series branch respectively, $\mathrm{S}$ is switch of series branch. Owing to series branch parallel in arc suppression coil, when single-phase grounding fault occurs, switch gets closed. By neutral zero sequence voltage $\mathrm{U}_{0}$ effect, $\mathrm{RL}$ series branch gives zero-state response: $u_{0}(t)=U \sin (\omega t+\psi)$. Among them, $\varnothing$ is conduction angle, its size depends on the switch closing time. Through the series branch, impedance is:

$Z=\sqrt{R^{2}+(\omega L)^{2}} \angle \arctan \left(\frac{\omega L}{R}\right)=|Z| \angle \varphi$

Through the series branch current is:

$i=\frac{U}{|Z|} \sin (\omega t+\psi-\varphi)-\frac{U}{|Z|} \sin (\psi-\varphi) e^{-\frac{t}{\tau}}$

According to the above formula, the current is divided into steady-state component and transient component. If $\varnothing=\varphi$, there exists no transient process, and the current directly accesses to the steady state. In addition, controlling the size of conduction angle $\varnothing$ and impedance angle $\varphi$, to longitudinal axis $\mathrm{i}=0$ as a reference, can make the series branch current wave up or down. If series branch resistance $R \rightarrow 0$, impedance Angle $\varphi \rightarrow 90^{\circ}$, with the conduction Angle different, the size of initial half-wave current amplitude changes as well.

Since the size of grounding resistance in fault point is large, with the increase of grounding resistance, the zero sequence voltage in the RL series branch decreases, and the branch produces initial half-wave which is small and cannot be monitored. Adjustment of the size of inductance in the series branch can avoid the incident effectively. At the same time, to reduce the influence of device on the system stability as far as possible, the conduction time of switch is adjusted in the series branch, making the RL series branch only produce initial half-wave cycle signal and the zero sequence current in fault line stack.

\section{THE THEORY OF FAULT LOCATION BASE ON FTU}

\subsection{FTU Main Characteristics}

Attached to the sustainable development of power distribution automation system, the power supply quality requirements improve with increase of the automation. For single-phase grounding fault in the small current grounding system, many traditional location methods cannot be implemented effectively. The reason is not only hardware conditions and the complexity of fault system, but also fault char- 


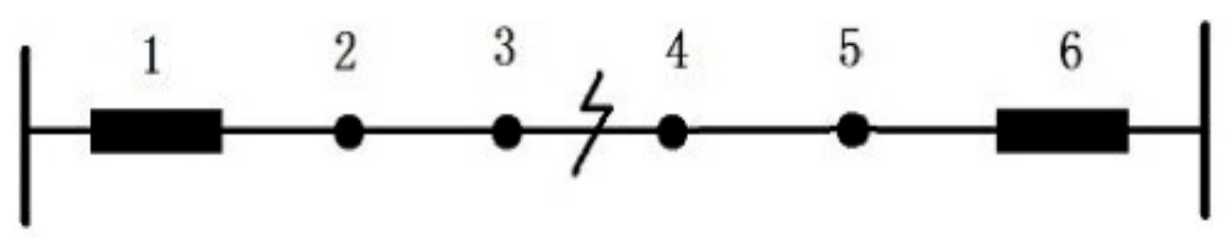

Fig. (2). Simple feeder network.

acteristic parameter extraction deficiency. Based on the characteristic of distribution network ring network structure, loop operation is opened, as the basis of distribution automation system, feeder automation technology plays an important role in small current system fault single- phase grounding fault by using FTU (Feeder Terminal Unit) fault location.

As a key technology of distribution automation, feeder automation technology is implemented to find fault location and isolation mainly, and FTU is the core equipment on the feeder automation technology. At present, the FTU can realize a variety of functions, including information collection and processing, parameter design, power loss protection, clock, SOE records and report, self-inspection and automatic recovery, remote control communication and protection function. FTU is used to implement single-phase grounding fault line selection and location in small current grounding system, that depends on information collection and processing mainly. Which is divided into remote signaling: collect remote signaling deflection, accident remote signaling and send state variables to main station or sub-station; telemetry: collection, conversion, processing module and send it to main station at the same time, accomplish voltage current measurement, including phase voltage, line voltage, the zero sequence voltage, line current, zero sequence current, active and reactive power, power factor; remote control: remote accept command from main station or sub-station, control the switch of column switching and trip, start storage, etc.

\subsection{Fault Location Theory}

When single-phase grounding fault occurs, FTU captures the fault signal from each monitory station on feeder lines. Uploading the fault characteristic signal to main station, and the main station carries on the analysis of the fault information processing. Fault signature is obvious for neutral nongrounding system, according to the grounding fault characteristics, using the signal of each monitoring stations can find out the grounding fault between two points on which feeder line is present to accomplish fault line selection and location. But for neutral arc suppression coil grounding system, due to compensation effect of arc suppression coil, fault signature is not obvious, which cannot implement fault line selection and location through the judgment size or direction of zero sequence, zero sequence power direction. This paper puts forward that RL series branch parallel in arc suppression coil to change zero sequence amplitude size in time, which fits FTU feeder automation technology. When single-phase grounding fault occurs, the switch of RL series branch switching in time, the current in initial half-wave by RL series branch and zero sequence current in fault line stacks, that changes the size of zero sequence residual current amplitude in time, and FTU on feeder lines monitoring the change, and the points which monitor the change are all in the fault loop. So, fault area location can be implemented [9, 10].

\subsection{Fault Location Matrix Algorithm}

Based on FTU feeder automation technology, fault location matrix algorithm is uploaded to transfer the useful fault information to master station system, which is analyzed in the process of treatment. Fault feeder branch for section isolation by using fault information has a generic algorithm. First of all, according to the structure of distribution network to get a network description matrix D, when system fault occurs, the monitoring point FTU fault information generates corresponding fault information matrix G. Through the network description matrix D and fault information matrix $G$ multiplication operation to get a matrix, the matrix normalized gets fault judgment matrix P. Through the description of fault judgment matrix $P$ can be learned that the fault point in fault feeder line is present between monitoring stations.

Specific methods are as follows. First of all, feeder network as shown in Fig. (2) matrix description.

The circuit breakers and FTU on the feeder network as nodes are numbers and the simple feeder network consists of six nodes, thus forming a $6 \times 6$ square matrix. If there is feeder connection between node I and node J, namely two nodes for adjacent nodes, all elements of row I column I and row $J$ column $J$ are 1 , the others are 0 . So it constitutes network description matrix $\mathrm{D}$ that reacts with feeder network topology.

$$
D=\left[\begin{array}{llllll}
0 & 1 & 0 & 0 & 0 & 0 \\
1 & 0 & 1 & 0 & 0 & 0 \\
0 & 1 & 0 & 1 & 0 & 0 \\
0 & 0 & 1 & 0 & 1 & 0 \\
0 & 0 & 0 & 1 & 0 & 1 \\
0 & 0 & 0 & 0 & 1 & 0
\end{array}\right]
$$

Also, the fault information matrix $G$ is a $6 \times 6$ square matrix. The traditional fault information detection method sets a fault current setting to all monitors. When node I is detected through the node current value is greater than the setting value, the fault information matrix row I column I element set 0 , otherwise, row I column I element set 1. According to the feeder network fault position as shown in Fig. (2), corresponding fault information matrix $G$ can be obtained for:

$$
G=\left[\begin{array}{llllll}
0 & 0 & 0 & 0 & 0 & 0 \\
0 & 0 & 0 & 0 & 0 & 0 \\
0 & 0 & 0 & 0 & 0 & 0 \\
0 & 0 & 0 & 1 & 0 & 0 \\
0 & 0 & 0 & 0 & 1 & 0 \\
0 & 0 & 0 & 0 & 0 & 1
\end{array}\right]
$$




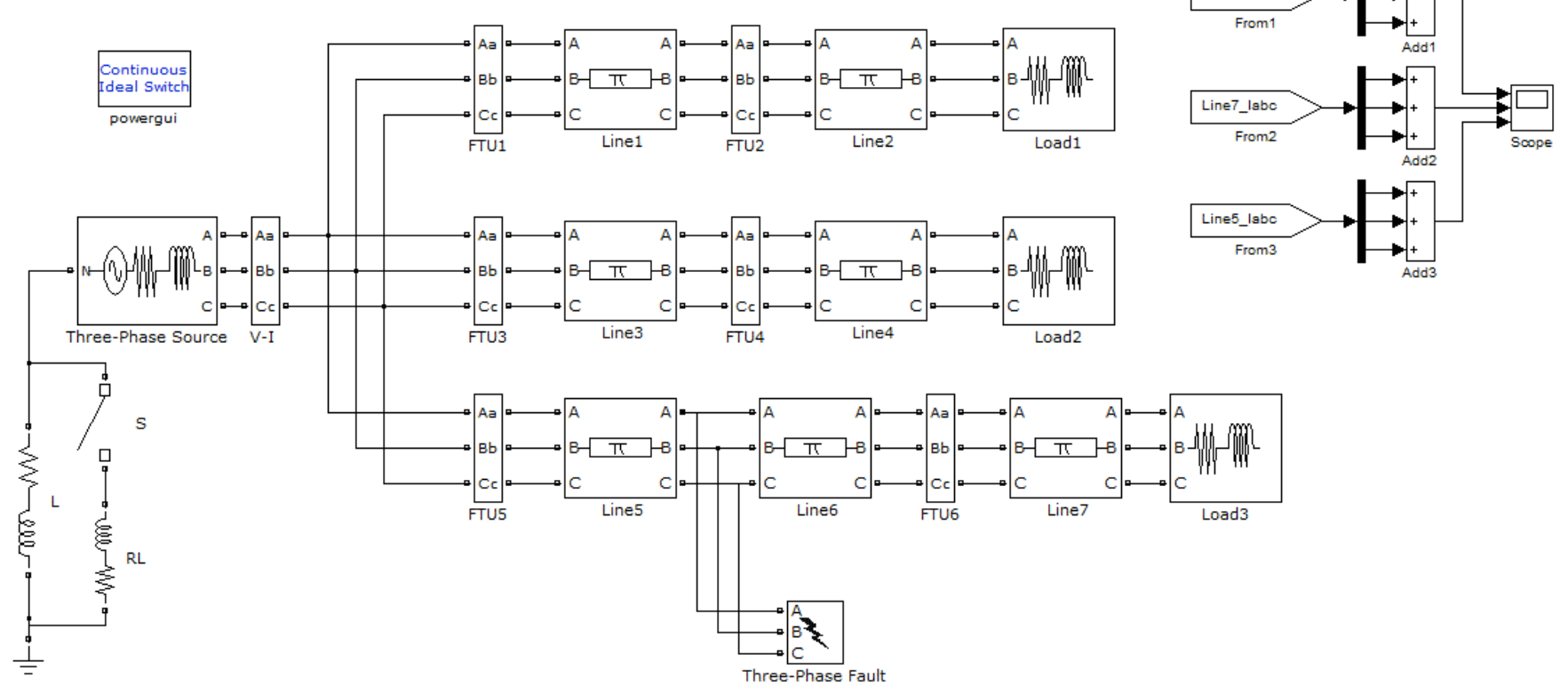

Fig. (3). Small current grounding System model.

Due to the presence of arc suppression coil, fault current value change in fault feeder branch becomes very complicated in each case, and cannot set the right setting. According to this paper, using zero sequence current change with FTU monitoring method, the monitoring data is no longer fault current value and setting value comparison. When fault occurs, all monitoring sites record fault current value through each node, after RL series branch switch get closed, based on the current value compared with earlier comparison before and after the change to replace the traditional method of the fault current value and setting value comparison.

Finally, the network description matrix and fault information matrix are multiplied and then are normalized. The matrix is fault judgment matrix $P$.

$P=g(D \times G)$

Specific normalization method is: for the elements in the matrix $\mathrm{D} \mathrm{d}_{\mathrm{mj}}, \mathrm{d}_{\mathrm{nj}} \ldots \ldots \mathrm{d}_{\mathrm{kj}}=1$, at the same time the elements $g_{j j}$ in the matrix $G$ for 1 , and $g_{m m} g_{n n} \ldots . . g_{k k}$ two elements for 0 at least, matrix $D \times G$ row $\mathrm{J}$ column $\mathrm{J}$ elements to normalizing treatment, namely all row $\mathrm{J}$ column $\mathrm{J}$ elements set 0 , the elements that is not conform to the above two conditions don't change. The fault judgment matrix $P$ based on Fig. (2):

$$
P=g(D \times G)=\left[\begin{array}{llllll}
0 & 0 & 0 & 0 & 0 & 0 \\
0 & 0 & 0 & 0 & 0 & 0 \\
0 & 0 & 0 & 1 & 0 & 0 \\
0 & 0 & 0 & 0 & 1 & 0 \\
0 & 0 & 0 & 1 & 0 & 1 \\
0 & 0 & 0 & 0 & 1 & 0
\end{array}\right]
$$

Fault section judgment can be obtained by fault judgment matrix $P$. The element in the matrix $P p_{i j} \wedge p_{j i}=1$, that is fault section between the node I and node J. Through the matrix $\mathrm{P}$ judgment $\mathrm{p}_{34} \wedge \mathrm{p}_{43}=1$, it verifies that the above feeder network fault section is located in between the node 3 and node 4 [11].

\section{SIMULATION TEST}

Using MATLAB / simulink software built neutral arc suppression coil grounding system model, as shown in Fig. (3).

The voltage level is $10 \mathrm{kV}$. Usually, the distribution network in order to avoid third harmonic comes from lowvoltage side to high-voltage in the main transformer, influences the quality of power supply system, so the main transformer adopts $\boldsymbol{Y} / \Delta$ connection, namely the low-voltage side of transformer adopts triangle connection, no neutral. Therefore, system needs grounding transformer for neutral. The system model in Fig. (3), the process that the main transformer step-down and equip grounding transformer for neutral equivalent to three-phase source with a neutral point. Three-phase source voltage level is $10 \mathrm{kV}$, frequency is $50 \mathrm{~Hz}$, source resistance is $0.8929 \Omega$ and source inductance is $16.58 \mathrm{mH}$.

Three-phase source neutral arc suppression coil L, its resistance $R=30 \Omega, L=1.5 \mathrm{H}$. $R L$ series branch $R=1 \Omega, L=10 \mathrm{H}$.

The model $10 \mathrm{kV}$ transmission lines adopt three-phase $\pi$ type equivalent line, that Line1 to Line7 respectively. Its positive and zero sequence resistances $R_{1}=0.01273 \Omega / \mathrm{km}$, $R_{0}=0.3864 \Omega / \mathrm{km} ;$ positive and zero sequence inductances $L_{1}=0.9337 \mathrm{mH} / \mathrm{km}, \quad L_{0}=4.1264 \mathrm{mH} / \mathrm{km} ;$ positive and zero sequence capacitances $C_{1}=12.74 \mu \mathrm{F} / \mathrm{km}, C_{0}=7.751 \mu \mathrm{F} / \mathrm{km}$. 


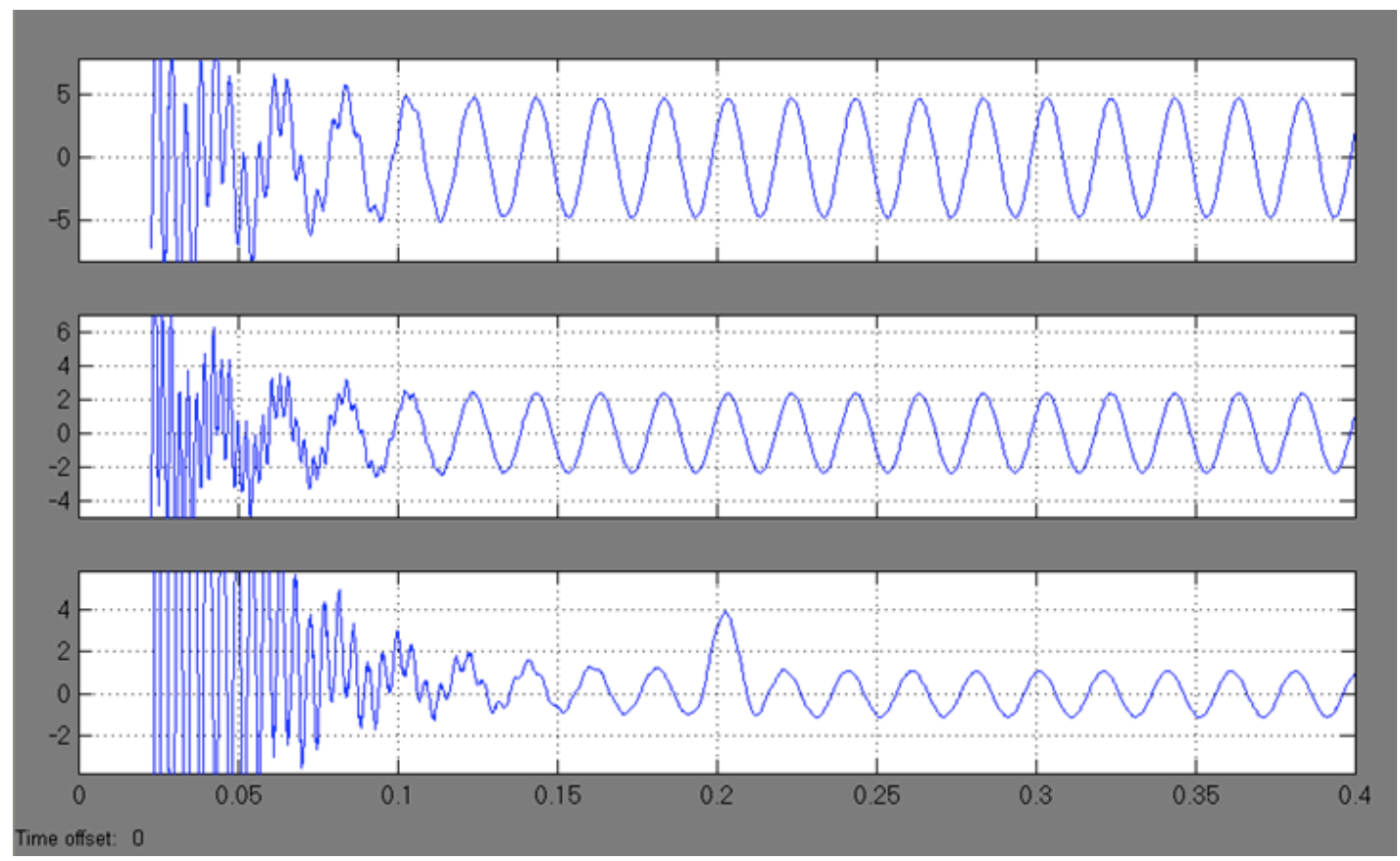

Fig. (4). Grounding resistance is 0 .

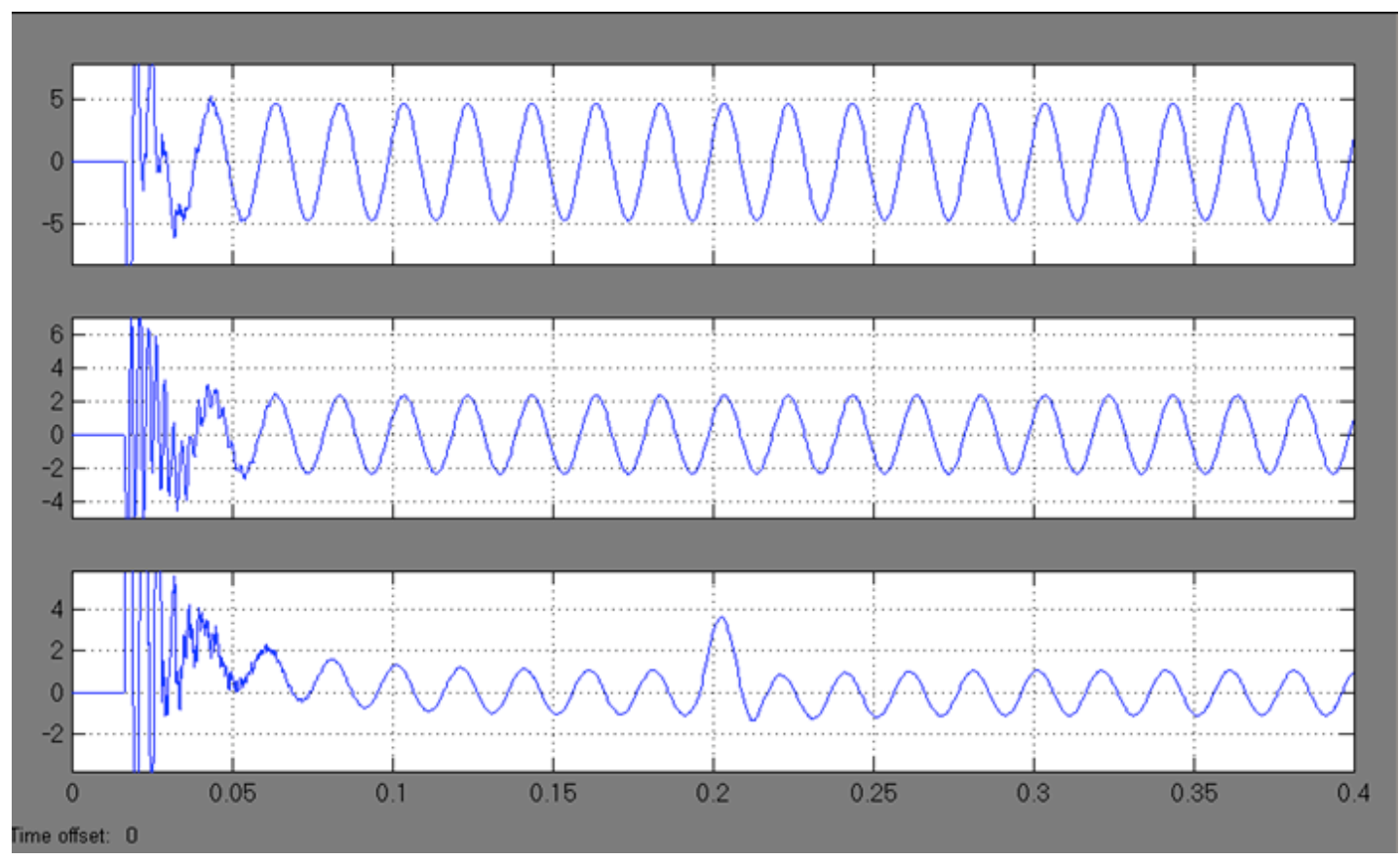

Fig. (5). Grounding resistance is $10 \Omega$.

In the system, Load1, Load2, Load3 are represented by the three line terminals of substation, that line load adopts for three-phase series RLC load, active power is 10MW.

The simulation system running time $0.4 \mathrm{~s}$, the point of fault time $1 / 60 \mathrm{~s}$, switching time $0.195 \mathrm{~s}$, closed time $0.005 \mathrm{~s}$. In the model, use three-phase VI measurement module as FTU, when single-phase grounding fault occurs in the line3, C phase of the system, zero sequence current wave in the non-fault lines and fault line as shown in Fig. (4):

As shown, the first waveform is zero sequence current waveform from the FTU3 in non-fault line, the middle wave- form is from FTU6 in fault line that after the fault point, the last zero sequence current waveform is from FTU5 in fault line that before the fault point. Obviously, in the switch of series branch closing time $0.195 \mathrm{~s}$ to $0.2 \mathrm{~s}$, the zero sequence current amplitude before the fault point has obvious change, but non-fault lines and fault lines after the fault point are almost same at this time. To prove this method is not affected by grounding resistance, the grounding resistance should be $10 \Omega$ and $1 \mathrm{k} \Omega$ on the system model simulation, the zero sequence current waveform is shown in Fig. (5), Fig. (6): 


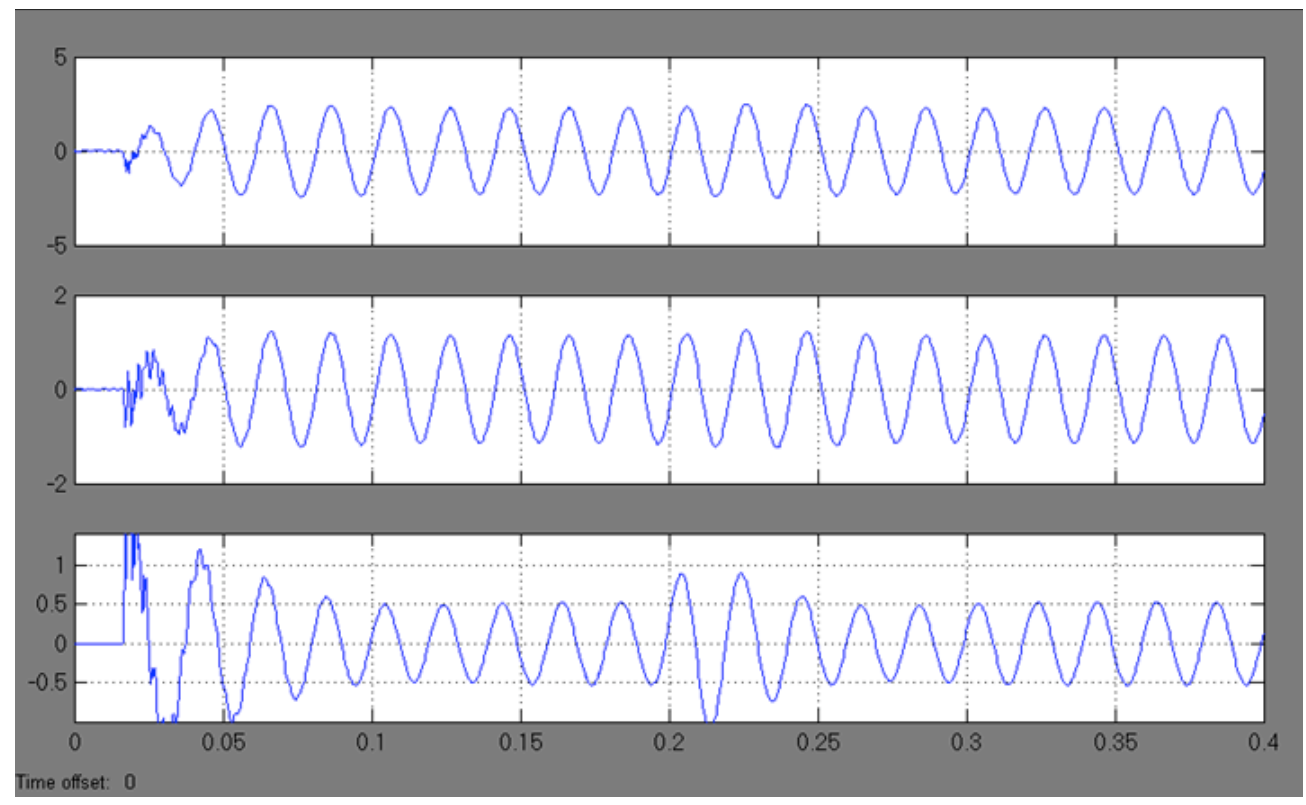

Fig. (6). Grounding resistance is $1 \mathrm{k} \Omega$.

As shown, even though the grounding resistance is larger, zero sequence current amplitude before the fault point still has obvious change than other current, therefore, the method in different resistance grounding is still effective [12].

\section{CONCLUSION}

Feeder automation technology is an important part of the distribution automation system. This paper, which changes zero sequence current using the method of RL series branch parallel in arc suppression coil and based on FTU feeder automation technology, fault area location is accomplished and using MATLAB simulation test the feasibility of this method is verified. With the traditional method of FTU monitoring control, this method does not need to preset FTU line current setting value. When fault occurs, the zero sequence current through each monitoring stations is recorded on feeder line by FTU, and then, in the switch of the series branch closing time, monitoring the change of zero sequence current can implement fault regional location. Compared with the residual current increment method, this method just affects arc suppression coil compensation degree in time, easy to keep the stability of the system, and not grounding resistance effect, suitable for a variety of complicated situation.

\section{CONFLICT OF INTEREST}

The authors confirm that this article content has no conflicts of interest.

\section{ACKNOWLEDGEMENTS}

Declared none.

\section{REFERENCES}

[1] W. Jun-yong and Z. Bao-hui, “A New Fault Location Algorithm for Single-Phase-to-Earth Fault in Non-Direct-Grounding Neutral System," Elect. Power Autom. Equip., vol. 20, no. 2, pp. 8-11, 2000.

[2] W. Xin-chao and S. Zai-zhong, "A new approach of fault location based on "S injecting signal"," Relay, vol. 29, no.7, pp. 9-12, 2001.

[3] W. Yu-mei and J. Tao, "Fault locating of $35 \mathrm{kV}$ transmission lines in coal mine based on traveling waves," Elect. Power Autom. Equip., vol. 26, no. 10, pp. 42-45, 2006.

[4] L. Meng-qiu, W. Yao-nan, W. Hui and W. Zheng-qiu, "A new approach on detecting the single-to ground fault location on power system with neutral unearthed," Proceedings of the CSEE, vol. 21, no.10, pp. 6-9, 2001.

[5] L. Jian, N. Jian-li and D. Yong-hui, "Distribution automation system”. China Water Resources and Hydro electrical Press: Beijing, 1999.

[6] X. Bai, S. Hong-chun and G. Feng, "Survey Methods of Fault Line Selection for Single-phase-to-earth Fault in Networks with Ungrounded Neutral," Relay, vol. 29, no. 4, pp. 17-20, 2001.

[7] W. Zheng and W. Jie, "Method of Single Phase Grounding Fault Locating for FTU in Networks with Ungrounded Neutral," Elect. Power Autom. Equip., vol. 23, no. 2, pp. 21-2, 2003.

[8] W. Jie and W. Zheng, "Reinvestigation for Approaches to Fault Location based on FTU in Power System with Neutral Unearthed," Relay, vol. 32, no. 22, pp. 29-33, 2004.

[9] Qing-quan, Y. Yi-han and Y. Qi-xun, "Application of DS Evidence Theory to Single-phase-to-ground Fault Line Detection," Autom. Elect. Power Syst., vol. 27, no. 21, pp. 25-38, 2003.

[10] Jian, N. Jian-li and D. Yu, "A unified matrix algorithm for fault section detection and isolation in distribution system," Autom. Elect. Power Syst., vol. 23, no. 1, pp. 31-33, 1999.

[11] Dao-bing and G. Xue-ping, "Locating Technique of Single-phase Grounding Fault based on Distribution Automation," Autom. Elect. Power Syst., vol. 34, no. 5, pp. 77-50, 2010.

[12] Z. Xiang-jun, K. Li, W. L. Chan, Y. Xiang-gen, and C. De-shu, "Earth Fault Feeder Detection with Information Fusion," Relay, vol. 30, no. 9, pp. 15-20, 2002.

(C) Jun et al.; Licensee Bentham Open.

This is an open access article licensed under the terms of the Creative Commons Attribution Non-Commercial License (http://creativecommons.org/licenses/by-nc/3.0/) which permits unrestricted, non-commercial use, distribution and reproduction in any medium, provided the work is properly cited. 